\title{
Role of Nociceptor Toll-like Receptor 4 (TLR4) in Opioid-Induced Hyperalgesia and Hyperalgesic Priming
}

\author{
D.Dioneia Araldi, ${ }^{1,2,3}$ Oliver Bogen, ${ }^{1,2,3}$ Paul G. Green, ${ }^{2,3,4}$ and $\odot$ Jon D. Levine ${ }^{1,2,3}$ \\ ${ }^{1}$ Department of Medicine, ${ }^{2}$ Department of Oral and Maxillofacial Surgery, ${ }^{3}$ Division of Neuroscience, and ${ }^{4}$ Department of Preventative and Restorative \\ Dental Sciences, University of California at San Francisco, San Francisco, California 94143
}

In addition to analgesia, opioids produce opioid-induced hyperalgesia $(\mathrm{OIH})$ and neuroplasticity characterized by prolongation of inflammatory-mediator-induced hyperalgesia (hyperalgesic priming). We evaluated the hypothesis that hyperalgesia and priming induced by opioids are mediated by similar nociceptor mechanisms. In male rats, we first evaluated the role of nociceptor Toll-like receptor 4 (TLR4) in $0 \mathrm{IH}$ and priming induced by systemic low-dose morphine (LDM, $0.03 \mathrm{mg} / \mathrm{kg}$ ). Intrathecal oligodeoxynucleotide antisense to TLR4 mRNA (TLR4 AS-ODN) prevented OIH and prolongation of prostaglandin $\mathrm{E}_{2}$ hyperalgesia (priming) induced by LDM. In contrast, high-dose morphine (HDM, $3 \mathrm{mg} / \mathrm{kg}$ ) increased nociceptive threshold (analgesia) and induced priming, neither of which was attenuated by TLR4 AS-ODN. Protein kinase $\mathrm{C} \varepsilon(\mathrm{PKC} \varepsilon)$ AS-ODN also prevented LDM-induced hyperalgesia and priming, whereas analgesia and priming induced by HDM were unaffected. Treatment with isolectin B4 (IB4)-saporin or SSP-saporin (which deplete IB4 ${ }^{+}$and peptidergic nociceptors, respectively), or their combination, prevented systemic LDM-induced hyperalgesia, but not priming. HDM-induced priming, but not analgesia, was markedly attenuated in both saporin-treated groups. In conclusion, whereas $\mathrm{OIH}$ and priming induced by LDM share receptor and second messenger mechanisms in common, action at TLR4 and signaling via PKC $\varepsilon$, HDM-induced analgesia, and priming are neither TLR4 nor PKC $\varepsilon$ dependent. OIH produced by LDM is mediated by both IB4 ${ }^{+}$and peptidergic nociceptors, whereas priming is not dependent on the same population. In contrast, priming induced by HDM is mediated by both IB4 ${ }^{+}$and peptidergic nociceptors. Implications for the use of low-dose opioids combined with nonopioid analgesics and in the treatment of opioid use disorder are discussed.

Key words: hyperalgesic priming; morphine; opioid-induced hyperalgesia (OIH); protein kinase epsilon (PKCE); toll-like receptor 4 (TLR4)

\section{Significance Statement}

Opioid-induced hyperalgesia $(\mathrm{OIH})$ and priming are common side effects of opioid agonists such as morphine, which acts at $\mu$-opioid receptors. We demonstrate that $\mathrm{OIH}$ and priming induced by systemic low-dose morphine (LDM) share action at Toll-like receptor 4 (TLR4) and signaling via protein kinase $\mathrm{C} \varepsilon(\mathrm{PKC} \varepsilon)$ in common, whereas systemic high-dose morphine (HDM)-induced analgesia and priming are neither TLR4 nor PKC $\varepsilon$ dependent. OIH produced by systemic LDM is mediated by isolectin B4-positive $\left(\mathrm{IB}^{+}{ }^{+}\right.$) and peptidergic nociceptors, whereas priming is dependent on a different class of nociceptors. Priming induced by systemic HDM is, however, mediated by both $\mathrm{IB}_{4}^{+}$and peptidergic nociceptors. Our findings may provide useful information for the use of low-dose opioids combined with nonopioid analgesics to treat pain and opioid use disorders.

\section{Introduction}

The majority of opioid agonists used in clinical practice act at $\mu$-opioid receptors (MORs) to produce analgesia, with some having additional activity at other opioid receptors (Trafton et al., 2000; Al-Hasani and Bruchas, 2011) and nonopioid receptors

\footnotetext{
Received April 29, 2019; revised May 31, 2019; accepted June 6, 2019.

Author contributions: D.A. and J.D.L. designed research; D.A. and 0.B. performed research; D.A., 0.B., and P.G.G. analyzed data; D.A., O.B., and J.D.L. wrote the paper.

This work was supported by the National Institutes of Health (Grants NS084545 and NS085831).

The authors declare no competing financial interests.

Correspondence should be addressed to Jon D. Levine at Jon.Levine@ucsf.edu.

https://doi.org/10.1523/JNEUROSCI.0966-19.2019

Copyright $\odot 2019$ the authors
}

(Lewis et al., 2010; Hutchinson et al., 2011; Due et al., 2012; Bai et al., 2014; Johnson et al., 2014; Ellis et al., 2016). MORs are distributed throughout the CNS and within peripheral tissues, neuronal and nonneuronal (Stein et al., 2003; Pathan and Williams, 2012). Action at MORs in the CNS, including in the midbrain (Pathan and Williams, 2012) and substantia gelatinosa of the spinal dorsal horn (Grudt and Williams, 1994; Pathan and Williams, 2012) are thought to be critical for opioid-induced analgesia. However, the mechanisms mediating the side effects of opioid analgesics are less well understood.

We recently demonstrated that, whereas systemic high-dose morphine (HDM, $3 \mathrm{mg} / \mathrm{kg}$; s.c.) increases nociceptive threshold (analgesia), low-dose morphine (LDM, $0.03 \mathrm{mg} / \mathrm{kg}$; s.c.) de- 
creases nociceptive threshold (hyperalgesia) (Ferrari et al., 2019). Measured well after administration of either LDM or HDM, when nociceptive threshold had returned to premorphine baseline, hyperalgesia induced by the direct-acting pronociceptive mediator prostaglandin $\mathrm{E}_{2}\left(\mathrm{PGE}_{2}\right)$ was markedly prolonged, a key feature of hyperalgesic priming (Ferrari et al., 2019). When animals were treated with an AS-ODN to MOR mRNA intrathecally, systemic LDM still induced priming and LDM OIH was only slightly attenuated (Ferrari et al., 2019), indicating that LDM-induced priming is not, and OIH is only partially, MOR dependent. In MOR antisense-treated rats, analgesia and priming induced by HDM were only partially attenuated; thus, the effects of both LDM and HDM are only partially MOR dependent (Ferrari et al., 2019). The receptor at which systemic LDM acts in the induction of $\mathrm{OIH}$ and priming and the second messengers involved remain unknown. Importantly, of those opioid analgesics used in clinical practice, many are also Toll-like receptor 4 (TLR4) agonists, including morphine (Watkins et al., 2009; Wang et al., 2012) and the morphine metabolite morphine-3glucuronide (M3G) (Lewis et al., 2010; Due et al., 2012). Indeed, some studies have implicated TLR4, an innate immunity pattern receptor (Mogensen, 2009) present on sensory neurons (Barajon et al., 2009), as the receptor mediating opioid-induced hyperalgesia (Lewis et al., 2010; Hutchinson et al., 2011; Due et al., 2012; Bai et al., 2014; Johnson et al., 2014; Ellis et al., 2016), whereas other studies led to contrasting results (Due et al., 2012; Ferrini et al., 2013; Johnson et al., 2014; Mattioli et al., 2014; Skolnick et al., 2014; Roeckel et al., 2016; Corder et al., 2017).

Two types of hyperalgesic priming with distinct cellular mechanisms have been distinguished (Araldi et al., 2015). Induction and expression of type I priming by inflammatory mediators or activation of protein kinase C $\varepsilon$ (PKC $\varepsilon$ ) (Aley et al., 2000; Parada et al., 2003b; Joseph and Levine, 2010b; Bogen et al., 2012) is maintained by ongoing protein translation in nerve terminals (Ferrari et al., 2013) occurring in isolectin B4-positive $\left(\mathrm{IB} 4^{+}\right.$) nociceptors (Joseph and Levine, 2010a). In contrast, maintenance of type II priming, induced by opioids, depends on simultaneous activation of Src and mitogen-activated protein kinase (MAPK) (Araldi et al., 2017a) and occurs in peptidergic neurons (Araldi et al., 2017a). Although we previously demonstrated that systemic administration of both LDM and HDM induces type I priming because they were both reversed by a protein translation inhibitor (Ferrari et al., 2019), the involvement of PKC $\varepsilon$ and the role of IB4 ${ }^{+}$and/or IB4 ${ }^{-}$nociceptors is unknown. In this study, we evaluated the role of TLR4 and PKC $\varepsilon$ in systemic LDM- and HDM-induced hyperalgesia and analgesia, respectively, and priming. We also evaluated the role of $\mathrm{IB}^{+}{ }^{+}$and peptidergic nociceptors.

\section{Materials and Methods}

Animals

All experiments were performed on 220-420 g adult male Sprague Dawley rats (Charles River Laboratories). Experimental animals were housed three per cage under a $12 \mathrm{~h}$ light/dark cycle in a temperature- and humidity-controlled animal care facility at the University of California, San Francisco. Food and water were available ad libitum. Nociceptive testing was performed between 9:00 A.M. and 5:00 P.M. Experimental protocols were approved by the Institutional Animal Care and Use Committee at the University of California at San Francisco and adhered to the National Institutes of Health Guide for the Care and Use of Laboratory Animals. Effort was made to minimize the number of animals used and their suffering.

\section{Testing mechanical nociceptive threshold}

Mechanical nociceptive threshold was quantified using an Ugo Basile Analgesymeter (Randall-Selitto paw-withdrawal device, Stoelting), which applies a linearly increasing mechanical force to the dorsum of a rat's hindpaw, as described previously (Taiwo and Levine, 1989; Taiwo et al., 1989; Araldi et al., 2015, 2017a; Ferrari and Levine, 2015). Rats were placed in cylindrical acrylic restrainers designed to provide ventilation and allow extension of the hind legs from lateral ports in the cylinder during the assessment of nociceptive threshold, thus minimizing restraint stress. To acclimatize rats to the testing procedure, they were placed in restrainers for $40 \mathrm{~min}$ before starting each training session (3 consecutive days of training) and for $30 \mathrm{~min}$ before experimental manipulations. Nociceptive threshold was defined as the force, in grams, at which the rat withdrew its paw. Baseline paw pressure mechanical nociceptive threshold was defined as the mean of the three readings taken before test agents were injected. In each experiment, only one paw per rat was used. Each experiment was performed on a different group of rats. Individuals performing the behavioral experiments were blinded to experimental interventions.

\section{Drugs and their administration}

The following compounds were used in experiments: morphine sulfate salt pentahydrate (a $\mu, \delta$, and $\kappa$ opioid receptor agonist) and $\mathrm{PGE}_{2}$ (a direct-acting hyperalgesic agent that sensitizes nociceptors), both from Sigma-Aldrich. The stock solution of $\operatorname{PGE}_{2}(1 \mu \mathrm{g} / \mu \mathrm{l})$ was prepared in $10 \%$ ethanol and additional dilution made with physiological saline $(0.9 \% \mathrm{NaCl})$, yielding a final ethanol concentration $<2 \%$. Morphine was dissolved in saline.

Intradermal drug administration was performed on the dorsum of the hindpaw using a 30-gauge hypodermic needle adapted to a $50 \mu \mathrm{l} \mathrm{Ham-}$ ilton syringe by a segment of PE-10 polyethylene tubing (Becton Dickinson). Importantly, in vivo control experiments have previously shown that the final concentration of ethanol $(2 \%)$ used to prepare the $\mathrm{PGE}_{2}$ solution alone had no effect on mechanical nociceptive threshold (Ferrari et al., 2016).

Morphine was administered subcutaneously at the nape of the neck (Araldi et al., 2018b). Rats received an injection of morphine ( 0.03 or 3 $\mathrm{mg} / \mathrm{kg}$ ) and the mechanical nociceptive threshold was evaluated 15, 30, 45, and $60 \mathrm{~min}$ after morphine administration (Ferrari et al., 2019). Systemic morphine was diluted in saline and administered subcutaneously (100 $\mu \mathrm{l} / 100 \mathrm{~g}$ body weight).

\section{ODNs AS to TLR4 and PKCE $m R N A$}

To investigate the role of TLR4 and PKC $\varepsilon$ in the hyperalgesia and priming induced by systemic administration of morphine, ODN AS or mismatch. (MM) for TLR4 and PKC $\varepsilon$ mRNA were administered intrathecally. The AS-ODN sequence for TLR4, 5' -AGG AAG TGA GAG TGC CAA CC-3', was directed against a unique region of rat TLR4 (UniProtKB database entry Q9QX05). The MM-ODN sequence, 5'-ACG ATG CGA GAG AGT CAC CG-3' for TLR4, corresponds to the antisense sequence with seven bases mismatched (denoted by bold letters). MMand AS-ODN to PKC $\varepsilon$ mRNA were prepared as described previously (Parada et al., 2003a). The AS-ODN sequence, 5' -GCC AGC TCG ATC TTG CGC CC-3', was directed against a unique sequence of rat PKC $\varepsilon$ mRNA. The corresponding GenBank (National Institutes of Health, Bethesda, MD) accession number and ODN position within the cDNA sequence are XM345631 and 226-245, respectively. We have previously shown that spinal intrathecal administration of AS-ODN with this sequence decreases PKC $\varepsilon$ in dorsal root ganglia (DRG) compared with rats administered with ODN mismatch (Parada et al., 2003a,b). The sequence of the MM-ODN, 5'-GCC AGC GCG ATC TTT CGC CC-3', corresponds to the PKC $\varepsilon$ antisense sequence with two bases mismatched (denoted by bold letters). All ODNs were synthesized by Life Technologies.

Before use, lyophilized ODNs were reconstituted in nuclease-free $0.9 \% \mathrm{NaCl}$ and then administered intrathecally at a dose of $6 \mu \mathrm{g} / \mu \mathrm{l}$ in a volume of $20 \mu \mathrm{l}$ (total of $120 \mu \mathrm{g}$ in $20 \mu \mathrm{l}$ ). AS- or MM-ODNs were injected daily for 3 consecutive days and on the fourth day, $\sim 17 \mathrm{~h}$ after the last ODN injection, morphine $(0.03$ or $3 \mathrm{mg} / \mathrm{kg}$ ) was injected system- 
ically ( $100 \mu \mathrm{l} / 100 \mathrm{~g}$ of body weight, s.c.) and the mechanical nociceptive threshold was evaluated $15,30,45$, and $60 \mathrm{~min}$ after morphine. At the end of the fourth day, rats again received a dose of AS- or MM-ODN for TLR4 or PKC $\varepsilon$. Twenty-four hours after the systemic administration of morphine, $\mathrm{PGE}_{2}(100 \mathrm{ng}$ in $5 \mu \mathrm{l}$ ) was injected intradermally and mechanical nociceptive threshold evaluated $30 \mathrm{~min}$ and $4 \mathrm{~h}$ later. Prolongation of hyperalgesia is defined by its continued presence $4 \mathrm{~h}$ after injection of $\mathrm{PGE}_{2}$ (Aley et al., 2000; Reichling and Levine, 2009; Ferrari et al., 2014; Araldi et al., 2015, 2017a, 2018a). As described previously (AlessandriHaber et al., 2003), rats were anesthetized with isoflurane $\left(2.5 \%\right.$ in $\left.\mathrm{O}_{2}\right)$ and ODN was injected intrathecally using a syringe (300 units/ $\mu \mathrm{l})$ attached to a 29-gauge needle inserted into the subarachnoid space between the L4 and L5 vertebrae. A total of $120 \mu \mathrm{g}$ of AS- or MM-ODN in a volume of $20 \mu \mathrm{l}$ was then injected. When anesthesia was stopped, rats regained consciousness, $\sim 2 \mathrm{~min}$ after the intrathecal injection. Use of intrathecal AS-ODN to attenuate the expression of proteins, essential for their role in nociceptor sensitization, is well supported by previous studies (Song et al., 2009; Su et al., 2011; Bogen et al., 2012; Quanhong et al., 2012; Sun et al., 2013; Araldi et al., 2015, 2016a, 2017a; Ferrari et al., 2016; Oliveira-Fusaro et al., 2017).

\section{Intrathecal administration of saporins}

IB4-saporin. IB4-saporin, an IB4 ${ }^{+}$nociceptor neurotoxin (Advanced Targeting Systems), was diluted in saline and a dose of $3.2 \mu \mathrm{g}$ in a volume of $20 \mu \mathrm{l}$ administered intrathecally $14 \mathrm{~d}$ before experiments. The dose and timing of IB4-saporin administration was chosen based on previous reports from our group and others (Vulchanova et al., 2001; Nishiguchi et al., 2004; Joseph et al., 2008; Joseph and Levine, 2010a; Araldi et al., 2015, 2016a, 2017b).

SSP-saporin. $\left[\mathrm{Sar}^{9}, \operatorname{Met}\left(\mathrm{O}_{2}\right)^{11}\right]$-substance P-saporin, a $\mathrm{SP}^{+}$nociceptor neurotoxin (SSP-Saporin, Advanced Targeting Systems) was diluted in saline and a dose of $100 \mathrm{ng}$ in a volume of $20 \mu \mathrm{l}$ was administered intrathecally $14 \mathrm{~d}$ before priming experiments. The addition of [ $\mathrm{Sar}^{9}$, $\operatorname{Met}\left(\mathrm{O}_{2}\right)^{11}$ ] to the substance $\mathrm{P}$ conjugated to saporin makes the agent more stable and potent than when substance $P$ alone is bound to saporin. The dose and pretreatment interval protocols were based on the studies of Wiley et al. (2007) and Choi et al. (2012), who observed no loss of intrinsic lumbar dorsal horn neurons expressing the neurokinin 1 (NK1) receptor in deeper laminae and prominent loss of NK1 receptor in laminae I, and functional studies by us and others (Khasabov et al., 2002; Vierck et al., 2003; Wiley et al., 2007; Choi et al., 2012; Weisshaar and Winkelstein, 2014; Kras et al., 2015; Araldi et al., 2016b, 2017b).

To administer the saporins, rats were briefly anesthetized with $2.5 \%$ isoflurane (Phoenix Pharmaceuticals) in $97.5 \% \mathrm{O}_{2}$. A 29-gauge hypodermic needle was then inserted, on the midline, between the L4 and L5 vertebrae, into the subarachnoid space. The control treatment consisted of intrathecal injection of the same volume of vehicle (saline). Rats regained consciousness $\sim 2$ min after stopping anesthesia. IB4-saporin or SSP-saporin had no effect on the mechanical nociceptive threshold per se (D.A. unpublished data). The groups that were treated intrathecally with the combination of saporins received IB4-saporin $(3.2 \mu \mathrm{g}$ in $10 \mu \mathrm{l})$ in the morning and SSP-saporin (100 ng in $10 \mu \mathrm{l})$ in the afternoon.

\section{SDS-PAGE and Western blotting}

To determine the efficacy of TLR4 antisense treatment, its expression in rat lumbar DRG was quantitated. Rats were killed by exsanguination while under isoflurane anesthesia $24 \mathrm{~h}$ after the last injection of ODN antisense (or mismatch) against TLR4 mRNA. L4 and L5 DRGs were surgically excised and stored at $-80^{\circ} \mathrm{C}$. DRGs were transferred into homogenization buffer (100 mm NaCl, 1 mm EDTA, 2\% SDS, 50 mм Tris$\mathrm{HCl}, \mathrm{pH}$ 7.4) supplemented with a protease inhibitor mixture (Roche Diagnostics) and manually homogenized with a hand-held plastic pestle. Proteins were solubilized by incubating the homogenates for $2 \mathrm{~h}$ at $37^{\circ} \mathrm{C}$ and $1400 \mathrm{rpm}$ in an Eppendorf Thermomixer and extracted from insoluble cell and tissue components by a 15 min centrifugation at $14,000 \mathrm{rpm}$ in a tabletop centrifuge. Protein concentration of all samples was determined using the micro BCA Protein Assay Kit (Pierce Biotechnology) with BSA as the standard. Mixtures of $40 \mu \mathrm{g}$ of protein per sample were denatured by boiling in sample buffer [3\% SDS, 10\% (v/v) Glycerol, 5\% (v/v) $\beta$-mercaptoethanol, 0.025 bromphenol blue, $62.5 \mathrm{~mm}$ Tris- $\mathrm{HCl}$, $\mathrm{pH} 6.8$ ] for $10 \mathrm{~min}$ and electrophoresed on $4-15 \%$ precast polyacrylamide gels (Bio-Rad) in $25 \mathrm{~mm}$ Tris containing $192 \mathrm{~mm}$ glycine and $0.1 \%$ SDS. Proteins were electrophoretically transferred to a nitrocellulose membrane using the semidry method [transfer time $2 \mathrm{~h}$ at $60 \mathrm{~mA} / \mathrm{gel}$ with $47.9 \mathrm{~mm}$ Tris, $38.9 \mathrm{~mm}$ Glycine, $0.038 \%$ SDS and 20\% (v/v) methanol]. The nitrocellulose membranes were saturated by shaking in antibody dilution buffer [5\% BSA in Tris-buffered saline containing $0.1 \%$ Tween 20, pH 7.4 TBST)] for $1 \mathrm{~h}$ at room temperature, cut in half at $\sim 75$ $\mathrm{kDa}$, and probed with either a mouse monoclonal anti-TLR4 (NB10056566 , 1:500, Novus Biologicals) or a rabbit polyclonal anti $\beta$-actin (ab8227, 1:1000, Abcam) antibody in antibody dilution buffer at $4^{\circ} \mathrm{C}$ overnight. Blots were then rinsed with TBST three times at room temperature (RT) 15 min each and probed with either an HRP-conjugated anti-mouse antibody (Pierce Biotechnology, 1:2500 in antibody dilution buffer) or an HRP-conjugated anti-rabbit antibody (GE Healthcare Life Sciences, 1:2500 in antibody dilution buffer) for $2 \mathrm{~h}$ at RT. The blotting membranes were rinsed with TBST ( 3 times at RT, 15 min each) and immunoreactivities visualized using the West Femto chemiluminescence detection system (Pierce Biotechnology). Results were analyzed using computer-assisted densitometry with levels of TLR4 immunoreactivity normalized with respect to the $\beta$-actin control levels in the same sample. The percentage decrease in TLR4 expression was calculated as follows: [normalized density for AS/normalized density for $\mathrm{MM} \times 100$ ] -100 (Summer et al., 2008; Alvarez et al., 2017).

\section{Data analysis}

All data are presented as mean \pm SEM of $n$ independent observations. Statistical comparisons were made using GraphPad Prism 7.0 statistical software. $p<0.05$ was considered statistically significant.

In the behavioral experiments, the dependent variable was change in mechanical paw-withdrawal threshold, expressed as percentage change from baseline. No significant difference in mechanical nociceptive thresholds was observed between before the systemic administration of morphine, and immediately before injection of $\mathrm{PGE}_{2}$ (average mechanical nociceptive threshold before priming stimuli (morphine): $140.8 \pm$ $1.311 \mathrm{~g}$; average mechanical nociceptive threshold before $\mathrm{PGE}_{2}$ injection: $139.3 \pm 1.301 \mathrm{~g} ; n=96$ rats; paired Student's $t$ test, $t_{(95)}=1.143, p=$ $0.2555)$. As specified in the figure legends, Student's $t$ test or two-way repeated-measures ANOVA, followed by Bonferroni post hoc test, was performed to compare the magnitude of the hyperalgesia or analgesia induced by morphine in the different groups, or to compare the effect produced by different treatments on the prolongation of the $\mathrm{PGE}_{2}$ induced hyperalgesia (evaluated $4 \mathrm{~h}$ after injection) with the control groups.

Western blotting results are presented as arbitrary units (a.u.) normalized to the reference protein, $\beta$-actin. A total of 12 rats were used in Figure $1 A$. Differences between groups treated with AS- and MM-ODN for TLR4 mRNA were analyzed using unpaired Student's $t$ test.

\section{Results}

\section{TLR4 dependence of systemic LDM-induced hyperalgesia} and priming

We have previously demonstrated that systemically administered LDM $(0.03 \mathrm{mg} / \mathrm{kg}$, s.c.) produces a decrease in mechanical nociceptive threshold $(\mathrm{OIH})$ and, when subsequently injected intradermally, markedly prolonged $\mathrm{PGE}_{2}$ hyperalgesia (priming) (Ferrari et al., 2019). We also demonstrated that MOR AS-ODN produced a small, albeit significant, attenuation of LDM $(0.03$ $\mathrm{mg} / \mathrm{kg}$ )-induced hyperalgesia and had no effect on LDM-induced priming (Ferrari et al., 2019). To evaluate whether action at TLR4 mediates the hyperalgesia and priming induced by LDM, we first evaluated whether intrathecal treatment with TLR4 AS-ODN attenuated the expression of TLR4 in DRGs. Evidence for antisense-induced reduction of TLR4 expression in DRGs can be seen in Western blots (pooled L4 and L5 DRG) from ODNtreated rats (Fig. 1A), in which we observed a $22.07 \pm 3.42 \%$ 
B

A
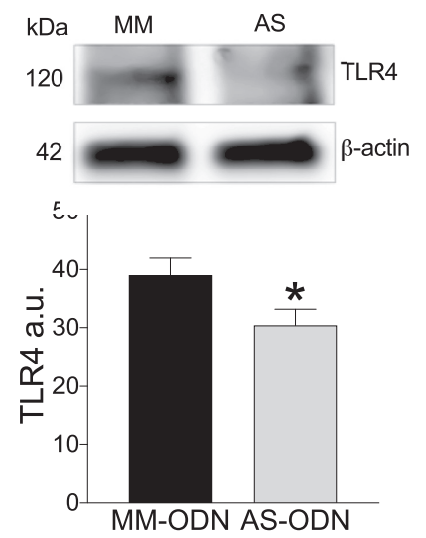

C
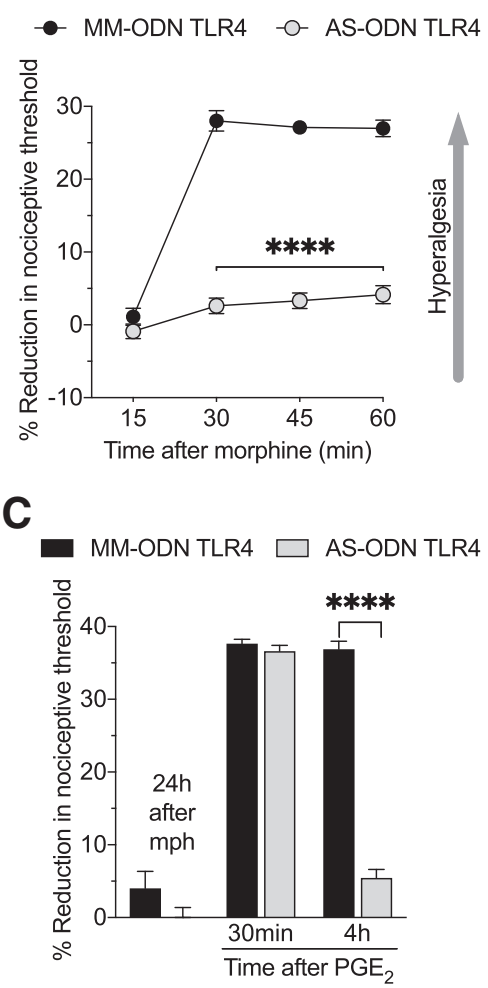

Figure 1. TLR4 dependence of 0 IH and priming induced by systemic LDM. $\boldsymbol{A}$. Western blot analysis of DRG extracts from rats injected with $120 \mu \mathrm{g}$ of antisense ODN/d for 3 consecutive days revealed a significant decrease in anti-TLR4 immunoreactivity when compared with the extracts derived from mismatch treated rats $\left(-22.07 \pm 3.42 \%\right.$, unpaired Student's $t$ test, ${ }^{*} p<0.05$, $n=6$ ). The calculated molecular weight of TLR4 is $96 \mathrm{kDa}$ (according to UniProtKB database entry Q90X05). The observed difference between the calculated and apparent molecular weight can be accounted for by the glycosylation of TLR4. $\beta$-actin, which was used as a loading control, has a calculated molecular weight of $\sim 42 \mathrm{kDa}$ (UniProtKB database entry P60771). Groups of rats were treated intrathecally with an AS-ODN (120 $\mu \mathrm{g}$ in $20 \mu \mathrm{l} / \mathrm{d}$, gray circles and bars; $B, C)$ or MM-0DN (120 $\mu \mathrm{g}$ in $20 \mu \mathrm{l} / \mathrm{d}$; black circles and bars; $\boldsymbol{B}, \boldsymbol{C}$ against TLR4 mRNA once a day for 3 consecutive days. $\boldsymbol{B}, 0 \mathrm{n}$ the fourth day, $\sim 17 \mathrm{~h}$ after the last intrathecal administration of ODNs, when the mechanical nociceptive threshold was not significantly different from pre-ODN baselines $\left(t_{(5)}=0.8305 ; p=0.4441\right.$, for the TLR4 MM-0DN-treated group and, $t_{(5)}=1.275 ; p=0.2582$, for the TLR4 AS-ODNtreated group, when the mechanical nociceptive threshold is compared before and $\sim 17 \mathrm{~h}$ after the third intrathecal injection of ODNs; paired Student's $t$ test), systemic LDM $(0.03 \mathrm{mg} / \mathrm{kg})$ was injected subcutaneously and the mechanical nociceptive threshold was evaluated 15, 30, 45, and 60 min after its injection. In the TLR4 AS-ODN-treated group, systemic LDM administration did not induce hyperalgesia measured at 30,45, and 60 min after administration, as is observed in the TLR4 MM-0DN-treated group $\left(F_{(1,10)}\right.$ $=236.45{ }^{* * * *} p<0.0001$; when the hyperalgesia in the TLR4 MM-ODN-treated group is compared with TLR4 AS-ODN-treated group at 30, 45 and 60 min after systemic LDM; two-way repeated-measures ANOVA followed by Bonferroni post hoc test). At the end of the fourth day, rats again received TLR4 AS- or MM-ODN. C, On the fifth day, $\sim 24 \mathrm{~h}$ after administration of systemic LDM when the mechanical nociceptive threshold was not significantly different from the premorphine $(\mathrm{mph})$ baselines $\left(t_{(5)}=0.6143\right.$; $p=0.5659$, for the TLR4 MM-ODN-treated group and, $t_{(5)}=1.234 ; p=0.2722$, for the TLR4 AS-0DN-treated group, when the mechanical nociceptive threshold is compared before and $24 \mathrm{~h}$ after systemic LDM; paired Student's $t$ test), PGE 2 (100 ng in $5 \mu l$ ) was injected intradermally and the mechanical nociceptive threshold was evaluated 30 min and $4 \mathrm{~h}$ later. In the group treated with TLR4 AS-ODN, which received systemic LDM, the prolongation of $\mathrm{PGE}_{2}$-induced hyperalgesia was inhibited $\left(F_{(1,10)}=93.78\right.$, ${ }^{* * * *} p<0.0001$; when the hyperalgesia in the TLR4 AS-ODN- and the MM-ODN-treated groups is compared at the fourth hour after intradermal PGE 2 ; two-way repeated-measures ANOVA followed by Bonferroni post hoc test). These findings indicate that both $0 \mathrm{HH}$ and priming induced by systemic LDM are TLR4 dependent. ( $n=6$ paws per group).

(in arbitrary units normalized to the reference protein) decrease in expression of TLR4 relative to the reference protein, $\beta$-actin (TLR4 in the antisense group was significantly less than in the mismatch group $\left(t_{10}=2.107 ; p=0.03\right.$, unpaired Student's $t$ test). The magnitude of the decrease in protein observed, which is an underestimate of change in sensory neurons because other cells in the DRG that express TLR4 would not be exposed to TLR4 AS-ODN, is similar to that observed by us for other proteins in DRG neurons after intrathecal AS-ODN (AlessandriHaber et al., 2003; Parada et al., 2003a; Dina et al., 2004; Ferrari et al.,
2019), as well as by other investigators (Lai et al., 2002, 2004) using intrathecal ODNs.

To determine whether TLR4, plays a role in the hyperalgesia and priming induced by systemic $\mathrm{LDM}(0.03 \mathrm{mg} / \mathrm{kg})$, rats received intrathecal AS-ODN or MMODN to TLR4 mRNA daily for $3 \mathrm{~d}$. On the fourth day, LDM $(0.03 \mathrm{mg} / \mathrm{kg})$ was injected systemically and mechanical nociceptive threshold measured 15, 30, 45, and $60 \mathrm{~min}$ later. In the group treated with TLR4 AS-ODN, LDM was not able to induce hyperalgesia compared with the TLR4 MM-ODN-treated group (Fig. $1 B$; $F_{(1,10)}=236.45, p<0.0001$, when the hyperalgesia in the TLR4 AS-ODN- and MM-ODN-treated groups is compared after systemic LDM; two-way repeatedmeasures ANOVA). At the end of the fourth day, rats again received TLR4 ASor MM-ODN. Twenty-four hours after systemic $\mathrm{LDM}, \mathrm{PGE}_{2}$ was injected intradermally and the mechanical nociceptive threshold was evaluated $30 \mathrm{~min}$ and $4 \mathrm{~h}$ later. Treatment with TLR4 ASODN completely prevented the prolongation of $\mathrm{PGE}_{2}$ hyperalgesia induced by LDM (Fig. 1C; $F_{(1,10)}=93.78, p<0.0001$, when the hyperalgesia in the TLR4 AS$\mathrm{ODN}$ - and MM-ODN-treated groups is compared at the fourth hour after $\mathrm{PGE}_{2}$; two-way repeated-measures ANOVA). Thus, hyperalgesia and hyperalgesic priming induced by systemic LDM $(0.03$ $\mathrm{mg} / \mathrm{kg}$ ) are strongly TLR4 dependent.

\section{Role of TLR4 in analgesia and priming induced by HDM}

We next determined whether analgesia and priming induced by systemic HDM (3 mg/ kg) (Ferrari et al., 2019) are also TLR4 dependent. Groups of rats were treated with AS- or MM-ODN for TLR4 mRNA daily for 3 consecutive days. Approximately $17 \mathrm{~h}$ after the last ODN injection, on the fourth day, morphine $(3 \mathrm{mg} / \mathrm{kg})$ was injected systemically and the mechanical nociceptive threshold evaluated $15,30,45$, and $60 \mathrm{~min}$ later. Analgesia induced by systemic morphine $(3 \mathrm{mg} / \mathrm{kg}$ ) was not different between the groups treated with TLR4 AS- and MMODN (Fig. 2A; $F_{(1,10)}=0.137, p=0.7184$, when the analgesia in the TLR4 AS-ODNand MM-ODN-treated groups is compared after systemic HDM; two-way repeated-measures ANOVA). Rats again received TLR4 AS- or MM-ODN intrathecally at the end of the fourth day. Twentyfour hours after $\mathrm{HDM}, \mathrm{PGE}_{2}$ was injected intradermally and the mechanical nociceptive threshold was evaluated $30 \mathrm{~min}$ and $4 \mathrm{~h}$ later. The prolongation of $\mathrm{PGE}_{2}$-induced hyperalgesia was present, without attenuation, in the group of rats treated with TLR4 ASODN (Fig. $2 B ; F_{(1,10)}=0.133, p=0.7231$, when the hyperalgesia in the TLR4 AS-ODN- and MM-ODN-treated groups is compared at the fourth hour after $\mathrm{PGE}_{2}$; two-way repeated-measures ANOVA), 


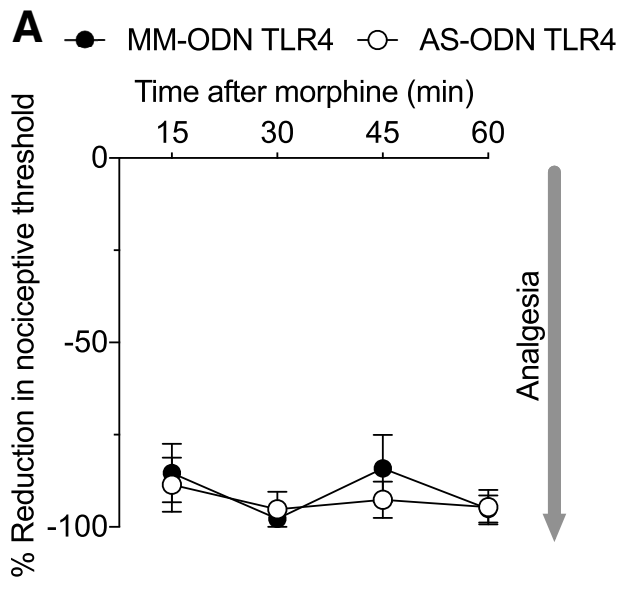

B

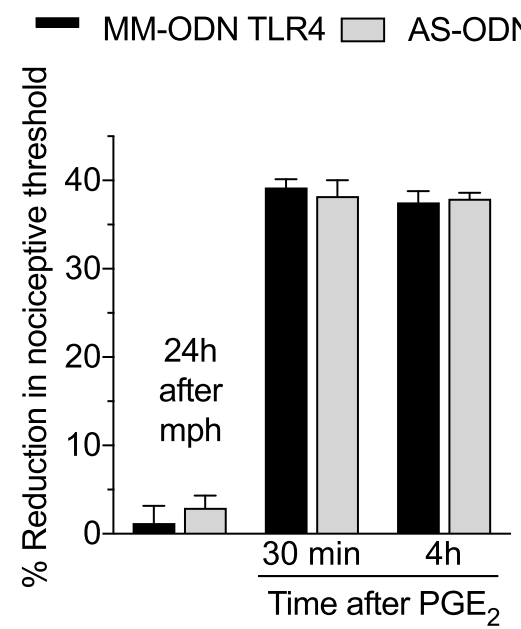

Figure 2. TLR4 independence for systemic HDM-induced analgesia and priming. Rats received intrathecal injections of AS-ODN (120 $\mu \mathrm{g}$ in $20 \mu \mathrm{l} / \mathrm{d}$; white circles and bars) or MM-0DN (120 $\mu \mathrm{g}$ in 20 $\mu \mathrm{l} / \mathrm{d}$; black circles and bars) against TLR4 mRNA daily for 3 consecutive days. $A, 0$ n the fourth day, $\sim 17 \mathrm{~h}$ after the last ODN injection, systemic HDM ( $3 \mathrm{mg} / \mathrm{kg}$ ) was injected subcutaneously and mechanical nociceptive threshold measured 15, 30, 45, and 60 min after its injection. Systemic HDM induced analgesia in both TLR4 AS- and MM-ODN-treated groups at all time points evaluated $\left(F_{(1,10)}\right.$ $=0.137, p=0.7184$, when the analgesia in the TLR4 AS-ODN- and the MM-ODN-treated groups is compared at 15, 30, 45, and 60 min after systemic HDM; two-way repeated-measures ANOVA followed by Bonferroni post hoc test). At the end of the fourth day, rats received another dose of TLR4ASor MM-0DN. B, Approximately $24 \mathrm{~h}$ after systemic HDM, when the mechanical nociceptive threshold was not significantly different from premorphine baseline $\left(t_{(5)}=0.1334 ; p=0.8991\right.$, for the MMODN-treated group, and $t_{(5)}=0.2548 ; p=0.8090$, for the AS-ODN-treated group, when the mechanical nociceptive threshold is compared before and $24 \mathrm{~h}$ after systemic HDM; paired Student's $t$ test), $\mathrm{PGE}_{2}(100 \mathrm{ng}$ in $5 \mu \mathrm{l}$ ) was injected intradermally and the mechanical nociceptive threshold at the injection site was evaluated 30 min and $4 \mathrm{~h}$ after its injection. In both the TLR4 AS- and MM-ODNtreated groups, the prolongation of $\mathrm{PGE}_{2}$-induced hyperalgesia was present $\left(\mathrm{ns}, F_{(1,10)}=0.133, p=\right.$ 0.7231, when the hyperalgesia in the TLR4 AS-ODN- and the MM-ODN-treated groups is compared at the fourth hour after intradermal PGE $_{2}$; two-way repeated-measures ANOVA followed by Bonferroni post hoc test), indicating that analgesia and priming induced by systemic HDM are both TLR4 independent. ( $n=6$ paws per group).

indicating that the analgesia and priming induced by HDM ( $3 \mathrm{mg} /$ $\mathrm{kg}$ ) are TLR4 independent. Thus, LDM and HDM act at different receptors to induce priming.

Role of PKC $\varepsilon$ in hyperalgesia and priming induced by systemic LDM

We have previously shown that the priming induced by systemic LDM $(0.03 \mathrm{mg} / \mathrm{kg})$ is type I because it is reversed by the protein translation inhibitor cordycepin administered at the nociceptor's central or peripheral terminals (Ferrari et al., 2013, 2019). Therefore, we evaluated whether a second messenger involved in the induction of type I priming, PKC $\varepsilon$ (Aley et al., 2000; Parada et al., 2003a) is involved in LDM $(0.03 \mathrm{mg} / \mathrm{kg})$-induced hyperalgesia and priming. Rats were treated with AS- or MM-ODN for PKC $\varepsilon$ mRNA daily for 3 consecutive days. On the fourth day, $\sim 17 \mathrm{~h}$ after the last ODN injection, LDM $(0.03 \mathrm{mg} / \mathrm{kg})$ was administered systemically and mechanical nociceptive threshold evaluated $15,30,45$, and 60 min later. The hyperalgesia induced by systemic LDM $(0.03 \mathrm{mg} / \mathrm{kg})$ was not observed in the PKC $\varepsilon$ AS-ODN-treated rats (Fig. $3 A ; F_{(1,10)}=217.5$, $p<0.0001$, when the hyperalgesia in the PKC $\varepsilon$ AS-ODN- and MMODN-treated groups is compared after systemic LDM; two-way repeated-measures ANOVA). Rats again received AS- or MM-ODN intrathecally at the end of the fourth day. Twenty-four hours after systemic LDM, $\mathrm{PGE}_{2}$ was injected intradermally and the mechanical nociceptive threshold was evaluated $30 \mathrm{~min}$ and $4 \mathrm{~h}$ later to assess for the presence of priming. Treatment with PKC $\varepsilon$ AS-ODN also markedly inhibited the prolongation of $\mathrm{PGE}_{2}$ hyperalgesia in LDMtreated rats (Fig. $3 B ; F_{(1,10)}=151.2, p<0.0001$, when the hyperalgesia in the PKC $\varepsilon$ AS-ODN- and MM-ODN-treated groups is compared at the fourth hour after $\mathrm{PGE}_{2}$; two-way repeatedmeasures ANOVA). These findings support the suggestion that hyperalgesia and priming induced by systemic LDM $(0.03 \mathrm{mg} / \mathrm{kg})$ share a dependence on PKC $\varepsilon$.

\section{Role of PKC $\varepsilon$ in analgesia and priming induced by systemic HDM}

We next investigated whether the analgesia and priming induced by systemic HDM (3 mg/kg) (Ferrari et al., 2019) are also PKC $\varepsilon$ dependent. Groups of rats were treated with AS- or MM-ODN for $\mathrm{PKC} \varepsilon$ daily for 3 consecutive days. Approximately $17 \mathrm{~h}$ after the last ODN injection, on the fourth day, HDM $(3 \mathrm{mg} / \mathrm{kg})$ was injected systemically and the mechanical nociceptive threshold evaluated 15, 30, 45, and $60 \mathrm{~min}$ later. The analgesia induced by systemic HDM (3 mg/kg) was not different between the groups treated with AS- and MM-ODN for PKC $\varepsilon$ mRNA (Fig. $4 A ; F_{(1,10)}$ $=0.2507, p=0.6274$, when the analgesia in the PKC $\varepsilon$ AS-ODNand MM-ODN-treated groups is compared after systemic HDM; two-way repeated-measures ANOVA). Rats again received $\mathrm{PKC} \varepsilon$ AS- or MM-ODN intrathecally at the end of the fourth day. Twenty-four hours after systemic $\mathrm{HDM}, \mathrm{PGE}_{2}$ was injected intradermally and the mechanical nociceptive threshold was evaluated 30 min and $4 \mathrm{~h}$ later. The prolongation of $\mathrm{PGE}_{2}$-induced hyperalgesia was present in groups treated with either AS- or MM-ODN for PKC $\varepsilon$ mRNA (Fig. $4 B ; F_{(1,10)}=1.043, p=0.3311$, when the hyperalgesia in the PKC $\varepsilon$ AS-ODN- and MM-ODNtreated groups is compared at the fourth hour after $\mathrm{PGE}_{2}$; twoway repeated-measures ANOVA), indicating that neither the analgesia nor the priming induced by systemic HDM $(3 \mathrm{mg} / \mathrm{kg})$ is PKC $\varepsilon$ dependent. These findings support the suggestion that LDM and HDM act via different signaling pathways downstream of TLR4 and MOR, respectively, to induce priming, with induction by LDM but not HDM being PKCe dependent. Whereas priming induced by HDM is PKC $\varepsilon$ independent, it is type I priming (Ferrari et al., 2019).

\section{Involvement of IB4 ${ }^{+}$and peptidergic nociceptors in} hyperalgesia but not priming induced by systemic LDM Type I priming, induced by local intradermal administration of inflammatory mediators, occurs in IB4 ${ }^{+}$nociceptors (Joseph and Levine, 2010a), whereas type II priming, induced by repeated local intradermal exposure to DAMGO (a potent MOR selective opioid agonist) occurs in peptidergic nociceptors (Araldi et al., 
A

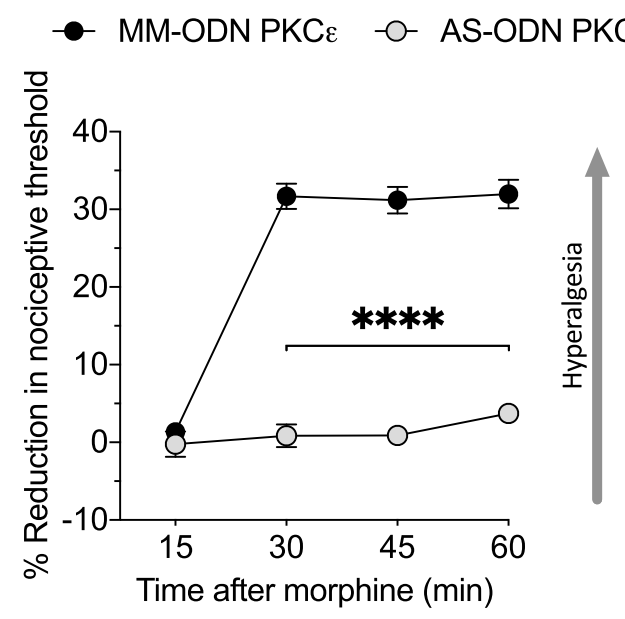

B

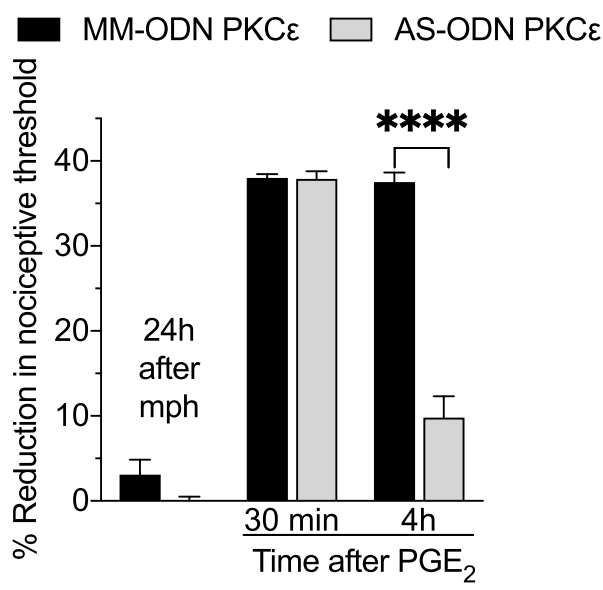

Figure 3. PKC $\varepsilon$ dependence of hyperalgesia and priming induced by systemically administered LDM. Rats received intrathecal injections of AS-ODN (120 $\mu \mathrm{g}$ in $20 \mu \mathrm{l} / \mathrm{d}$; gray circles and bars) or MM-ODN (120 $\mu \mathrm{g}$ in $20 \mu \mathrm{l} / \mathrm{d}$; black circles and bars) against PKC $\varepsilon$ mRNA daily for 3 consecutive days. $A, 0$ the fourth day, $\sim 17 \mathrm{~h}$ after the last $0 \mathrm{DN}$ injection, when the mechanical nociceptive threshold was not significantly different from the pre-0DN baseline $\left(t_{(5)}=1.904\right.$; $p=0.1152$, for the MM-ODN-treated group, and $t_{(5)}=0.7324 ; p=0.4968$, for the AS-ODNtreated group, when the mechanical nociceptive threshold is compared before and after systemic LDM; paired Student's $t$ test), LDM $(0.03 \mathrm{mg} / \mathrm{kg})$ was injected subcutaneously and the mechanical nociceptive threshold was evaluated $15,30,45$, and 60 min after its injection. Systemic LDM did not induce hyperalgesia at 30, 45 and 60 min after administration in the group treated with AS-0DN for PKC $\varepsilon\left(F_{(1,10)}=217.5,{ }^{* * * *} p<0.0001\right.$, when the hyperalgesia in the PKC $\varepsilon$ AS-ODN- and the MM-ODN-treated groups is compared 30, 45 and 60 min after systemic LDM; two-way repeated-measures ANOVA followed by Bonferroni post hoc test). At the end of the fourth day, rats again received PKC $\varepsilon$ AS- or MM-ODN. $B$, On the fifth day, $\sim 24 \mathrm{~h}$ after systemic LDM, when the mechanical nociceptive threshold was not significantly different from premorphine $(\mathrm{mph})$ baseline $\left(t_{(5)}=0.8811 ; p=0.4186\right.$, for the MM-0DN-treated group, and $t_{(5)}=0.5649 ; p=0.5965$, for the AS-ODN-treated group, when the mechanical nociceptive threshold is compared before and $24 \mathrm{~h}$ after systemic LDM; paired Student's $t$ test), $\mathrm{PGE}_{2}$ (100 ng in $5 \mu$ l) was injected intradermally and the mechanical nociceptive threshold evaluated $30 \mathrm{~min}$ and $4 \mathrm{~h}$ later. $\mathrm{PGE}$ did not induce prolonged hyperalgesia in the AS-ODN-treated group $\left(F_{(1,10)}=151.2,{ }^{* * *} p<0.0001\right.$, when the hyperalgesia in the PKC $\varepsilon$ AS-ODN- and the MMODN-treated groups is compared at the fourth hour after intradermal $\mathrm{PGE}_{2} ;$ two-way repeatedmeasures ANOVA followed by Bonferroni post hoc test), indicating that both systemic LDM-induced hyperalgesia and priming are PKC $\varepsilon$ dependent. ( $n=6$ paws per group).

2018a). To determine whether hyperalgesia and priming, induced by systemic LDM $(0.03 \mathrm{mg} / \mathrm{kg})$ are dependent on IB4 ${ }^{+}$ and/or peptidergic nociceptors, we intrathecally injected IB4saporin, which destroys IB4 ${ }^{+}$nociceptors; SSP-saporin, which destroys peptidergic nociceptors; or their combination (IB4-

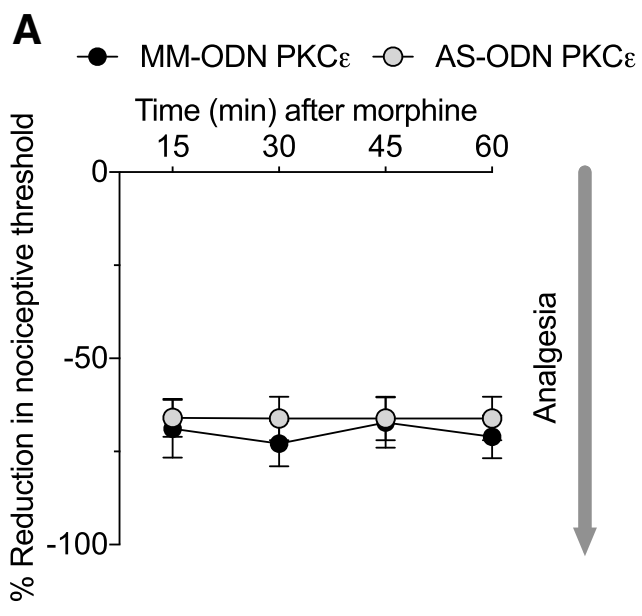

\section{B MM-ODN PKCE $\square$ AS-ODN PKC $\varepsilon$}

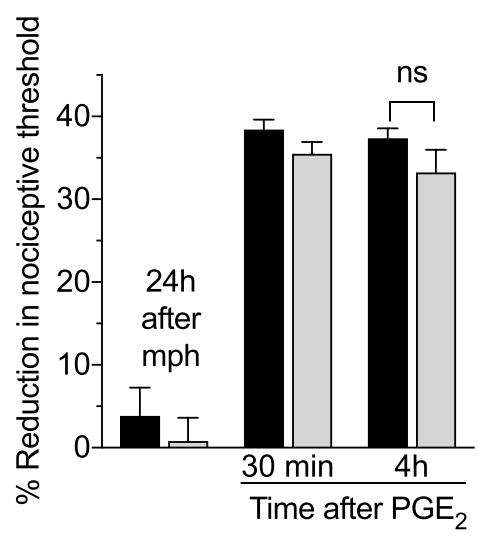

Figure 4. PKC $\varepsilon$ independence of analgesia and priming induced by systemic HDM. Rats received intrathecal injections of AS-ODN (120 $\mu \mathrm{g}$ in $20 \mu \mathrm{l} / \mathrm{d}$; white circles and bars) or MMODN (120 $\mu$ g in $20 \mu \mathrm{l} / \mathrm{d}$; black circles and bars) against PKC $\varepsilon$ mRNA daily for 3 consecutive days. $A$, On the fourth day, $\sim 17 \mathrm{~h}$ after the last ODN injection, systemic HDM ( $3 \mathrm{mg} / \mathrm{kg}$ ) was injected subcutaneously and the mechanical nociceptive threshold was evaluated 15,30,45, and $60 \mathrm{~min}$ after its injection. In both the PKC $\varepsilon$ AS- and MM-ODN-treated groups, systemic HDM induced analgesia at all time points evaluated $\left(F_{(1,10)}=0.2507, p=0.6274\right.$, when the analgesia in the AS-ODN- and the MM-ODN-treated groups is compared at $15,30,45$, and 60 min after systemic HDM; two-way repeated-measures ANOVA followed by Bonferroni post hoc test). At the end of the fourth day, rats received another dose of PKC $\varepsilon$, AS- or MM-ODN. B, Approximately $24 \mathrm{~h}$ after systemic HDM, when the mechanical nociceptive threshold was not significantly different from the premorphine baseline $\left(t_{(5)}=0.1395 ; p=0.8945\right.$, for the MM-ODN-treated group, and $t_{(5)}$ $=1.536 ; p=0.1852$, for the AS-ODN-treated group, when the mechanical nociceptive threshold is compared before and after systemic HDM; paired Student's $t$ test), $\mathrm{PGE}_{2}(100 \mathrm{ng}$ in $5 \mu \mathrm{l}$ ) was injected intradermally and the mechanical nociceptive threshold was evaluated 30 min and $4 \mathrm{~h}$ after injection. The prolongation of $\mathrm{PGE}_{2}$-induced hyperalgesia was present in both the PKC $\varepsilon$ AS- and MM-ODN-treated groups (ns $=$ not significant, $F_{(1,10)}=1.043, p=0.3311$, when the hyperalgesia in the AS-ODN- and the MM-ODN-treated groups is compared at the fourth hour after intradermal PGE 2 , two-way repeated-measures ANOVA followed by Bonferroni post hoc test). These findings support the suggestion that analgesia and priming induced by systemic HDM are both $\mathrm{PKC} \varepsilon$ independent. ( $n=6$ paws per group).

saporin and SSP-saporin). Fourteen days later, we injected LDM $(0.03 \mathrm{mg} / \mathrm{kg})$ systemically and evaluated the mechanical nociceptive threshold 15, 30, 45, and 60 min later. Systemic LDM was not able to produce hyperalgesia in rats pretreated with IB4saporin, SSP-saporin, or their combination (Fig. $5 A ; F_{(3,20)}=$ $135.3, p<0.0001$, when the hyperalgesia in the vehicle- and saporins-treated groups is compared after systemic LDM; twoway repeated-measures ANOVA). Twenty-four hours later, $\mathrm{PGE}_{2}$ was injected intradermally and the mechanical nociceptive 
A
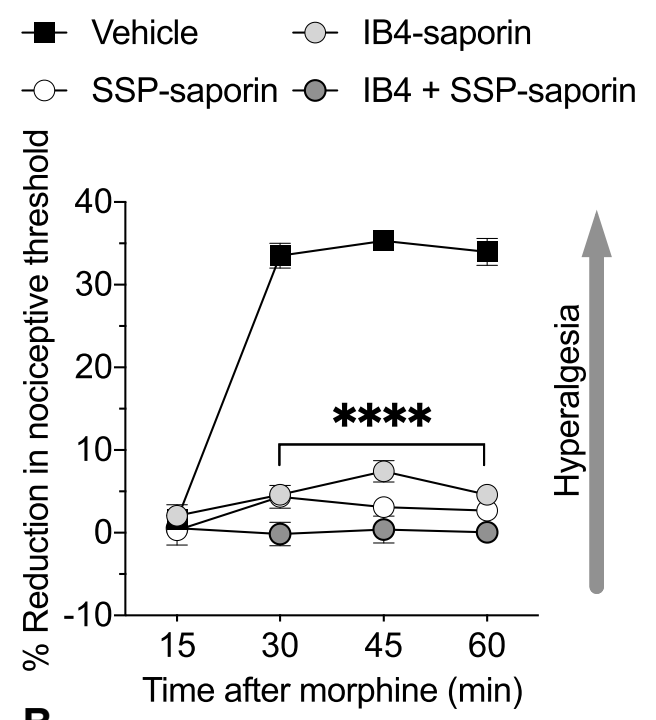

B

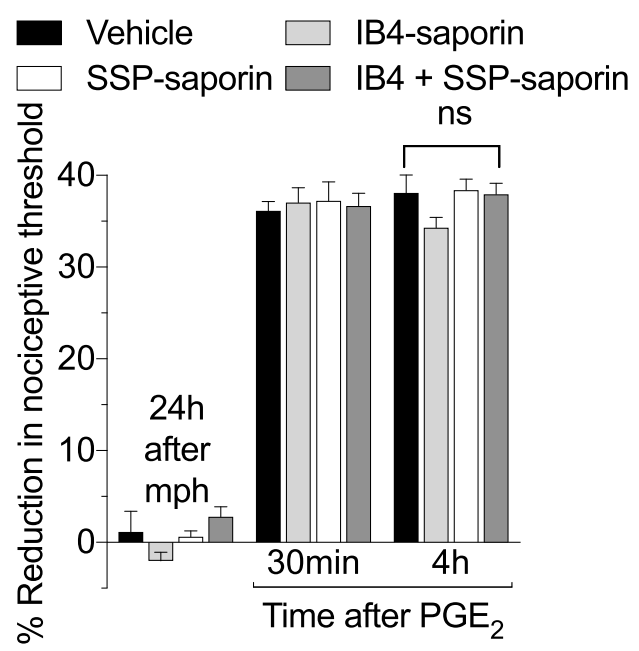

Figure 5. Role of IB4 ${ }^{+}$and peptidergic nociceptors in hyperalgesia and priming induced by LDM. Rats received an intrathecal injection of vehicle ( $20 \mu \mathrm{l}$; black squares and bars), IB4saporin (3.2 $\mu \mathrm{g}$ in $20 \mu \mathrm{l}$; gray circles and bars), SSP-saporin (100 ng in $20 \mu \mathrm{l}$; white circles and bars), or the combination of IB4-saporin (3.2 $\mu \mathrm{g}$ in $10 \mu \mathrm{l}$ ) and SSP-saporin (100 ng in $10 \mu$; black circles and dotted bars). $\boldsymbol{A}$, Fourteen days later, a time at which the mechanical nociceptive threshold was not different from the pre-vehicle and pre-saporin administration baseline $\left(t_{(5)}\right.$ $=0.107 ; p=0.9190$, for the vehicle-treated group, $t_{(5)}=0.667 ; p=0.5343$, for the IB4saporin-treated group, $t_{(5)}=1.150 ; p=0.1842$, for the SSP-saporin-treated group, and $t_{(5)}=$ $0.128 ; p=0.9031$, for the combination of saporins-treated group, when the mechanical nociceptive threshold is compared before and $14 \mathrm{~d}$ after intrathecal treatments; paired Student's $t$ test), LDM (0.03 mg/kg) was injected subcutaneously and the mechanical nociceptive threshold was evaluated 15, 30, 45, and 60 min after LDM injection. Systemic LDM-induced hyperalgesia was blocked at 30,45, and 60 min after systemic LDM in all three groups: those previously treated with IB4-saporin, those previously treated with SSP-saporin, and those previously treated with their combination $\left(F_{(3.20)}=135.3{ }^{* * * *} p<0.0001\right.$; when the hyperalgesia in the vehicle- and the saporin-treated groups is compared at 30,45 , and 60 min after systemic LDM; two-way repeated-measures ANOVA followed by Bonferroni post hoc test). $\boldsymbol{B}$, Twenty-four hours later, at which time the mechanical nociceptive threshold was not different from the premorphine baseline $\left(t_{(5)}=1.772 ; p=0.1366\right.$, for the vehicle-treated group, $t_{(5)}=0.5462$; $p=0.6084$, for the IB4-saporin-treated group, $t_{(5)}=1.169 ; p=0.1322$, for the SSP-saporintreated group, and $t_{(5)}=1.746 ; p=0.1412$, for the combination of saporin-treated group, when the mechanical nociceptive threshold is compared before and after systemic LDM; paired Student's $t$ test), PGE $(100 \mathrm{ng}$ in $5 \mu \mathrm{l}$ ) was injected intradermally and the mechanical nociceptive threshold was evaluated $30 \mathrm{~min}$ and $4 \mathrm{~h}$ later. The prolongation of $\mathrm{PGE}_{2}$ hyperalgesia was present in all groups treated with vehicle, IB4-saporin, SSP-saporin, and the combination of saporins (ns = not significant, $F_{(3,20)}=1.46, p=0.2562$; when the hyperalgesia in the threshold was evaluated $30 \mathrm{~min}$ and $4 \mathrm{~h}$ later. Prolongation of $\mathrm{PGE}_{2}$-induced hyperalgesia was present, unattenuated, in all three saporin-treated groups (Fig. $5 B ; F_{(3,20)}=1.46, p=0.2562$, when the hyperalgesia in the vehicle- and saporins-treated groups is compared at the fourth hour after $\mathrm{PGE}_{2}$; two-way repeatedmeasures ANOVA). Thus, our findings support the suggestion that hyperalgesia induced by systemic LDM is dependent on an overlapping population of nociceptors that are both $\mathrm{IB} 4{ }^{+}$and peptidergic, the weakly IB4 ${ }^{+}$nociceptors, whereas its priming is dependent on a different class of nociceptors. We do not exclude, however, a contribution of $\mathrm{IB}^{+}{ }^{+}$or peptidergic nociceptors to priming.

\section{Involvement of $\mathrm{IB}^{+}{ }^{+}$and IB4 ${ }^{-}$nociceptors in priming induced by systemic HDM}

In rats treated $14 \mathrm{~d}$ prior with intrathecal IB4-saporin, SSPsaporin, or their combination, analgesia induced by systemic $\operatorname{HDM}(3 \mathrm{mg} / \mathrm{kg})$ was not attenuated (Fig. $6 A ; F_{(3,20)}=1.529, p=$ 0.2377 , when the analgesia in the vehicle-, IB4-saporin-, SSPsaporin-, and IB4- and SSP-saporin-treated groups is compared at 15, 30, 45, and 60 min after systemic HDM; two-way repeatedmeasures ANOVA), compatible with the suggestion that analgesia induced by systemic HDM is mediated by action at MORs in the CNS (Lipp, 1991; Jensen, 1997; Aicher et al., 2000; Abbadie et al., 2001; Corder et al., 2017). Twenty-four hours later, $\mathrm{PGE}_{2}$ was injected intradermally and the mechanical nociceptive threshold evaluated $30 \mathrm{~min}$ and $4 \mathrm{~h}$ later. The prolongation $(4 \mathrm{~h})$ but not the acute $\left(30 \mathrm{~min}\right.$ ) phase of $\mathrm{PGE}_{2}$-induced hyperalgesia was markedly attenuated in the group previously treated with SSP-saporin, but also partially inhibited in the group treated with IB4-saporin without additional inhibition by the combination of saporins (Fig. $6 B ; F_{(3,20)}=27.32, p<0.0001$; when the hyperalgesia in the vehicle- and in the three saporin-treated groups is compared at the fourth hour after $\mathrm{PGE}_{2}$; two-way repeated-measures ANOVA). These findings support the suggestion that priming induced by HDM, which is type I (Ferrari et al., 2019), is mediated by a population of nociceptors different, at least in part, from those mediating priming induced by systemic LDM, whereas HDM-induced analgesia is most likely mediated by an action of HDM on neurons in the CNS (Aicher et al., 2000; Abbadie et al., 2001).

\section{Discussion}

Opioid analgesics such as morphine and fentanyl, widely used for the treatment of moderate-to-severe pain, act at MORs (Matthes et al., 1996; Sora et al., 1997) distributed throughout the PNS and CNS, including in nociceptors and neurons in the dorsal horn of the spinal cord and discrete brain regions (Mansour et al., 1986; Pathan and Williams, 2012). Recent literature has provided evidence for a role of the primary afferent nociceptor in an especially problematic opioid side effect, OIH (Corder et al., 2017) and we have recently shown that opioid analgesics are also able to induce hyperalgesic priming, a neuroplastic change in nociceptors characterized by a prolongation of the mechanical hyperalgesia induced by inflammatory mediators, prototypically $\mathrm{PGE}_{2}$ (Araldi et al., 2015, 2017a, 2018a,b; Ferrari et al., 2019). In the present study, we evaluated the relationship between $\mathrm{OIH}$ and priming,

\section{$\leftarrow$}

vehicle- and saporins-treated groups is compared at the fourth hour after intradermal $\mathrm{PGE}_{2}$ two-way repeated-measures ANOVA followed by Bonferroni post hoc test). These findings demonstrate that systemic LDM acts in both classes of nociceptors to induce hyperalgesia, but not priming, in the peripheral terminal of the nociceptor. ( $n=6$ paws $/ 6$ rats per group). 
A
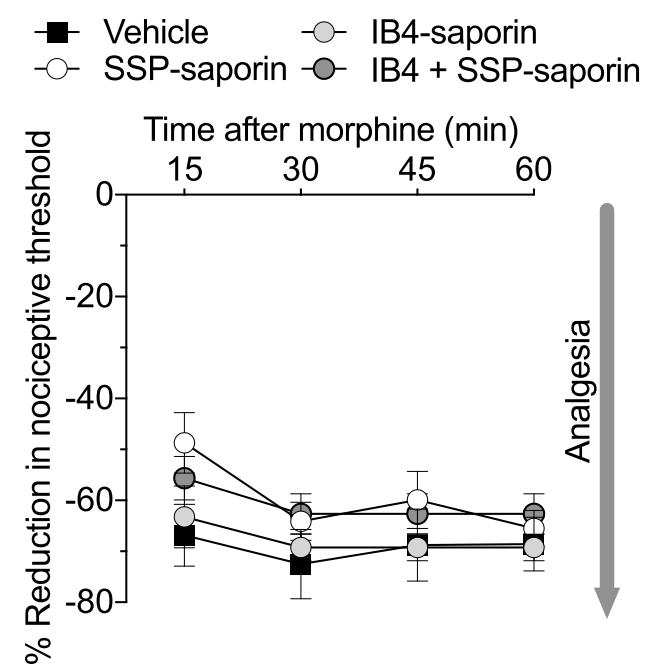

B

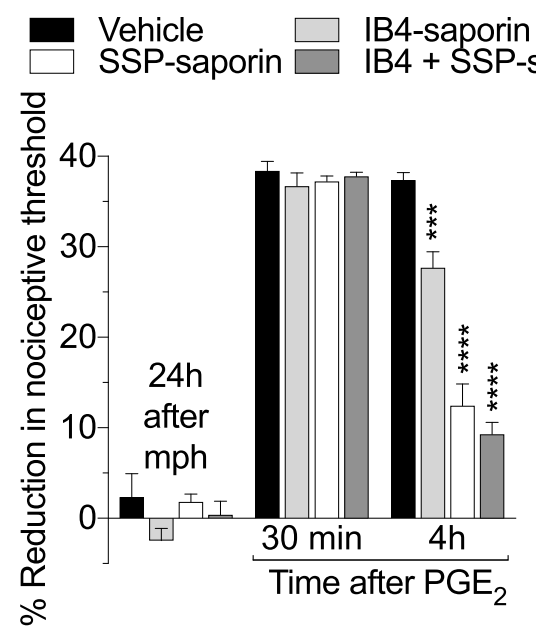

Figure 6. Role of IB4 ${ }^{+}$and peptidergic nociceptors in analgesia and priming induced by systemic HDM. Rats received intrathecal vehicle ( $20 \mu$ l; black squares and bars), IB4-saporin (3.2 $\mu \mathrm{g}$ in $20 \mu \mathrm{l}$; gray circles and bars), SSP-saporin (100 ng in $20 \mu$; white circles and bars), or the combination of IB4-saporin (3.2 $\mu \mathrm{g}$ in $10 \mu \mathrm{l}$ ) and SSP-saporin (100 ng in $10 \mu$; black circles and dotted bars). $\boldsymbol{A}$, Fourteen days later, HDM ( $3 \mathrm{mg} / \mathrm{kg}$ ) was injected subcutaneously and the mechanical nociceptive threshold was evaluated 15, 30, 45, and 60 min after HDM injection. HDM-induced analgesia was observed in all four treated-groups, without any attenuation, at any time point $\left(F_{(3,20)}=1.529, p=0.2377\right.$; when the analgesia in the vehicle-, IB4-saporin-, SSP-saporin-, and combination of saporin-treated groups is compared at 15, 30, 45, and $60 \mathrm{~min}$ after systemic HDM; two-way repeated-measures ANOVA followed by Bonferroni post hoc test). $\boldsymbol{B}$, Twenty-four hours after systemic HDM, a time at which the mechanical nociceptive threshold was not different from the premorphine baseline $\left(t_{(5)}=0.5423 ; p=0.6109\right.$, for the vehicletreated group, $t_{(5)}=1.557 ; p=0.1801$, for the IB4-saporin-treated group, $t_{(5)}=0.7324 ; p=$ 0.4968 , for the SSP-saporin-treated group, and $t_{(5)}=1.536 ; p=0.1852$, for the combination of saporin-treated group, when the mechanical nociceptive threshold is compared before and after systemic HDM; paired Student's $t$ test), PGE $_{2}(100 \mathrm{ng}$ in $5 \mu \mathrm{l}$ ) was injected intradermally and the mechanical nociceptive threshold was evaluated $30 \mathrm{~min}$ and $4 \mathrm{~h}$ later. In the group treated with IB4-saporin, $\mathrm{PGE}_{2}$ hyperalgesia was partially attenuated at the fourth hour $\left(F_{(3,20)}\right.$ $\left.=27.32,{ }^{* * *} p=0.0001\right)$, whereas in the group previously treated with SSP-saporin, the prolongation of $\mathrm{PGE}_{2}$ hyperalgesia was markedly attenuated $\left(F_{(3,20)}=27.32,{ }^{* * * *} p<0.0001\right.$; when the hyperalgesia in the vehicle- and in the three saporin-treated groups is compared at the fourth hour after intradermal PGE $_{2}$; two-way repeated-measures ANOVA followed by Bonferroni post hoc test), indicating that systemic HDM mainly requires peptidergic nociceptors to develop priming, but not analgesia, in the peripheral terminal of the nociceptor. Because adding IB4-saporin to SSP-saporin did not produce a further decrease, the small contribution of IB4-saporin is likely due to the overlapping population of weakly peptidergic IB4 ${ }^{+}$nociceptors ( $n=6$ paws $/ 6$ rats per group). induced by systemic administration of a clinical opioid analgesic, morphine, evaluating the receptors mediating these opioid effects, the underlying nociceptor second messenger mechanisms, and the population of nociceptors that mediate each opioid effect.

Because opioids are agonists at TLR4 (an innate immunity pattern receptor) (Hutchinson et al., 2010a,b; 2011; Wang et al., 2012; Jacobsen et al., 2014) as well as MOR, and both receptors are present on nociceptors (Barajon et al., 2009; Corder et al., 2017), we examined the role of nociceptor TLR4 in the pronociceptive effects of systemic LDM. Attenuation of DRG TLR4 with intrathecal AS-ODN all but eliminated both OIH and priming induced by LDM. These findings support nociceptor TLR4 as an important target for these effects of systemic LDM. The treatment with TLR4 AS-ODN did not, however, affect the analgesia and priming induced by systemic HDM. These effects differed markedly from those of LDM in two ways. First, systemic HDM induced analgesia rather than hyperalgesia; even administration of intrathecal MOR AS-ODN did not uncover hyperalgesia in response to HDM (Ferrari et al., 2019). Second, priming induced by HDM is MOR dependent (Ferrari et al., 2019) and not TLR4 dependent, indicating that systemic HDM is not an agonist at nociceptor TLR4.

It has been proposed that morphine can act on MORs expressed by microglia to initiate OIH (Ferrini et al., 2013). It has also been suggested that morphine can act on TLR4 present in the microglia to mediate OIH (Hutchinson et al., 2011). However, a more recent study using multiple histological approaches and highly sensitive RNA-seq of acutely purified adult mice spinal microglia, in contrast to previous findings in vitro and in vivo (Stiene-Martin et al., 1998; Turchan-Cholewo et al., 2008; Horvath et al., 2010; Ferrini et al., 2013), did not find evidence for MOR expression in microglia (Corder et al., 2017). Thus, whereas TLR4 on microglia may trigger their activation by binding damage-associated molecular patterns released from neurons or by binding morphine itself, this last point remains controversial (Hutchinson et al., 2010b; Ferrini et al., 2013). Additional studies suggest that TLR4 is not required for microglial activation by morphine (Fukagawa et al., 2013) or for opioid tolerance and hyperalgesia (Mattioli et al., 2014). Thus, whereas our findings do not exclude an effect of systemic LDM and HDM on microglia, taken together, a substantial literature supports the suggestion that systemic LDM is acting on TLR4 present in nociceptors to induce hyperalgesia and priming.

Although LDM-induced $\mathrm{OIH}$ and priming share signaling by the same second messenger, PKC $\varepsilon$, the effects of LDM and HDM differed with respect to the role of this second messenger in priming. Further,whereas $\mathrm{PKC} \varepsilon$, which has been implicated in type I hyperalgesic priming (Aley et al., 2000; Ferrari et al., 2014), was necessary for both OIH and priming induced by LDM, it is not necessary for priming induced by HDM. The protein translation inhibitor cordycepin, which reverses type I priming (Ferrari et al., 2013), did reverse priming induced by systemic HDM, as well as by systemic LDM (Ferrari et al., 2019). Although PKC $\varepsilon$, which is involved in the induction of type I priming (Aley et al., 2000; Ferrari et al., 2014), including that induced by LDM, did not play a role in HDM-induced priming, type I priming can be induced by $\mathrm{PKC} \varepsilon$-independent mechanisms such as ryanodine- and fentanyl-induced calcium release from the endoplasmic reticulum (Khomula et al., 2017; Araldi et al., 2018b).

To identify the nociceptor population at which LDM acts to induce $\mathrm{OIH}$ and priming and HDM acts to induce priming, we treated groups of rats with IB4-saporin, a neurotoxin for IB4 ${ }^{+}$ 
Table 1. Mechanisms mediating hyperalgesia, analgesia, and priming induced by LDM and HDM

\begin{tabular}{|c|c|c|c|c|}
\hline & \multicolumn{2}{|l|}{ LDM } & \multicolumn{2}{|l|}{ HDM } \\
\hline & $\mathrm{OIH}$ & Priming & Analgesia & Priming \\
\hline Receptors & $\mathrm{MOR}^{a}$ and TLR4 & TLR4 & $\mathrm{MOR}^{a}$ & $\mathrm{MOR}^{a}$ \\
\hline Second messengers & Protein translation ${ }^{a}$ and $\mathrm{PKC} \varepsilon$ & Protein translation ${ }^{a}$ and $\operatorname{PKC} \varepsilon$ & Protein translation ${ }^{a}$ & Protein translation ${ }^{a}$ \\
\hline Neuronal population & IB4 ${ }^{a}$ and peptidergic & Neither IB4 ${ }^{a}$ nor peptidergic & Neither IB4 ${ }^{a}$ nor peptidergic & IB4 ${ }^{a}$ and peptidergic \\
\hline
\end{tabular}

${ }^{a}$ Ferrari et al., 2019.

nociceptors, SSP-saporin, a neurotoxin for peptidergic nociceptors, or both saporins (Araldi et al., 2017a, 2018b). Although OIH and priming induced by LDM are both TLR4 mediated and PKC $\varepsilon$ dependent, lesioning $\mathrm{IB}^{+}{ }^{+}$and peptidergic nociceptors had different effects. For rats treated with either IB4-saporin or SSP-saporin, LDM no longer produced hyperalgesia $(\mathrm{OIH})$, which is consistent with systemic LDM-induced hyperalgesia being mediated by the $\mathrm{IB}^{+}{ }^{+}$and weakly peptidergic nociceptor population. In contrast, neither saporin alone or in combination attenuated LDM-induced priming. The class of nociceptors that mediates systemic LDM-induced priming remains to be determined. Although the analgesia induced by HDM was also intact after administration of IB4-saporin and SSP-saporin alone or in combination, compatible with an extensive literature that opioids induce analgesia by action at MORs on neurons in the CNS (Grudt and Williams, 1994; Stein et al., 2003; Pathan and Williams, 2012), priming induced by HDM was partially attenuated in the group treated with IB4-saporin, markedly attenuated in the SSP-saporin-treated group, and not significantly further attenuated in rats treated with the combination of saporins. Because adding IB4-saporin to SSP-saporin did not produce a further decrease in priming induced by systemic HDM, the small effect of IB4-saporin is likely due to the overlapping of weakly IB4 ${ }^{+}$and peptidergic class of nociceptors (Fang et al., 2006). Thus, priming induced by LDM and HDM occurs in different populations of neurons.

We recently demonstrated that priming produced in the peripheral nociceptor terminal by intrathecal fentanyl was not prevented by pretreatment with the combination of saporins, compatible with the presence of a novel class of nociceptors in which both fentanyl (Araldi et al., 2018b) and LDM act to induce priming. Approximately $20 \%$ of $\mathrm{TRPV}^{+}{ }^{+}$nociceptors are negative for both $\mathrm{IB}^{+}{ }^{+}$and peptidergic markers, indicating the existence of a substantial class of novel C-fiber afferents (Cavanaugh et al., 2011). We previously proposed that type I priming induced by direct activation of PKC $\varepsilon$ is dependent on $\mathrm{IB} 4{ }^{+}$nociceptors (Joseph and Levine, 2010a) and type II priming induced by intradermal DAMGO is dependent on peptidergic nociceptors (Araldi et al., 2017a); however, this cannot be applied for priming induced by systemic LDM and HDM. These data indicate complex effects of systemic LDM and HDM in the terminals of IB4 ${ }^{+}$ and/or peptidergic, and a novel class of nociceptors. Also, studies have demonstrated that at the level of the peripheral nociceptor terminal, there is behaviorally relevant specificity and selective regulation (Abrahamsen et al., 2008; Cavanaugh et al., 2009) with which our present data are in agreement because hyperalgesia and priming induced by systemic LDM and HDM are mediated by different subsets of nociceptors.

The previous and current findings, and proposed mechanisms involved in systemic LDM- and HDM-induced OIH and analgesia, respectively, and priming by both LDM and HDM are summarized in Table 1. Understanding the mechanisms and classes of nociceptors in which opioids such as fentanyl, morphine, and DAMGO act to induce hyperalgesia and priming may help to develop improved opioid analgesics with fewer side effects to treat chronic pain. For example, the use of low-dose opioids in combination with nonopioid analgesics to produce opioidsparing effects might have unintended consequences and shared mechanisms for OIH and priming may suggest novel approaches to the treatment of opioid use disorder by reversing mechanisms that maintain type I priming (Ferrari et al., 2013, 2019; Araldi et al., 2018b).

\section{References}

Abbadie C, Pasternak GW, Aicher SA (2001) Presynaptic localization of the carboxy-terminus epitopes of the mu opioid receptor splice variants MOR-1C and MOR-1D in the superficial laminae of the rat spinal cord. Neuroscience 106:833-842.

Abrahamsen B, Zhao J, Asante CO, Cendan CM, Marsh S, Martinez-Barbera JP, Nassar MA, Dickenson AH, Wood JN (2008) The cell and molecular basis of mechanical, cold, and inflammatory pain. Science 321:702-705.

Aicher SA, Sharma S, Cheng PY, Liu-Chen LY, Pickel VM (2000) Dual ultrastructural localization of mu-opiate receptors and substance $p$ in the dorsal horn. Synapse 36:12-20.

Alessandri-Haber N, Yeh JJ, Boyd AE, Parada CA, Chen X, Reichling DB, Levine JD (2003) Hypotonicity induces TRPV4-mediated nociception in rat. Neuron 39:497-511.

Aley KO, Messing RO, Mochly-Rosen D, Levine JD (2000) Chronic hypersensitivity for inflammatory nociceptor sensitization mediated by the epsilon isozyme of protein kinase C. J Neurosci 20:4680-4685.

Al-Hasani R, Bruchas MR (2011) Molecular mechanisms of opioid receptordependent signaling and behavior. Anesthesiology 115:1363-1381.

Alvarez P, Bogen O, Green PG, Levine JD (2017) Nociceptor interleukin 10 receptor 1 is critical for muscle analgesia induced by repeated bouts of eccentric exercise in the rat. Pain 158:1481-1488.

Araldi D, Ferrari LF, Levine JD (2015) Repeated mu-opioid exposure induces a novel form of the hyperalgesic priming model for transition to chronic pain. J Neurosci 35:12502-12517.

Araldi D, Ferrari LF, Levine JD (2016a) Adenosine-A1 receptor agonist induced hyperalgesic priming type II. Pain 157:698-709.

Araldi D, Ferrari LF, Levine JD (2016b) Gi-protein-coupled 5-HT1B/D receptor agonist sumatriptan induces type I hyperalgesic priming. Pain 157:1773-1782.

Araldi D, Ferrari LF, Levine JD (2017a) Hyperalgesic priming (type II) induced by repeated opioid exposure: maintenance mechanisms. Pain 158: 1204-1216.

Araldi D, Ferrari LF, Green P, Levine JD (2017b) Marked sexual dimorphism in 5-HT1 receptors mediating pronociceptive effects of sumatriptan. Neuroscience 344:394-405.

Araldi D, Ferrari LF, Levine JD (2018a) Role of GPCR (mu-opioid)receptor tyrosine kinase (epidermal growth factor) crosstalk in opioidinduced hyperalgesic priming (type II). Pain 159:864-875.

Araldi D, Khomula EV, Ferrari LF, Levine JD (2018b) Fentanyl induces rapid onset hyperalgesic priming: type I at peripheral and type II at central nociceptor terminals. J Neurosci 38:2226-2245.

Bai L, Zhai C, Han K, Li Z, Qian J, Jing Y, Zhang W, Xu JT (2014) Toll-like receptor 4-mediated nuclear factor-kappaB activation in spinal cord contributes to chronic morphine-induced analgesic tolerance and hyperalgesia in rats. Neurosci Bull 30:936-948.

Barajon I, Serrao G, Arnaboldi F, Opizzi E, Ripamonti G, Balsari A, Rumio C (2009) Toll-like receptors 3, 4, and 7 are expressed in the enteric nervous system and dorsal root ganglia. J Histochem Cytochem 57:1013-1023.

Bogen O, Alessandri-Haber N, Chu C, Gear RW, Levine JD (2012) Generation of a pain memory in the primary afferent nociceptor triggered by PKCepsilon activation of CPEB. J Neurosci 32:2018-2026. 
Cavanaugh DJ, Lee H, Lo L, Shields SD, Zylka MJ, Basbaum AI, Anderson DJ (2009) Distinct subsets of unmyelinated primary sensory fibers mediate behavioral responses to noxious thermal and mechanical stimuli. Proc Natl Acad Sci U S A 106:9075-9080.

Cavanaugh DJ, Chesler AT, Bráz JM, Shah NM, Julius D, Basbaum AI (2011) Restriction of transient receptor potential vanilloid-1 to the peptidergic subset of primary afferent neurons follows its developmental downregulation in nonpeptidergic neurons. J Neurosci 31:10119-10127.

Choi JI, Koehrn FJ, Sorkin LS (2012) Carrageenan induced phosphorylation of akt is dependent on neurokinin-1 expressing neurons in the superficial dorsal horn. Mol Pain 8:4.

Corder G, Tawfik VL, Wang D, Sypek EI, Low SA, Dickinson JR, Sotoudeh C, Clark JD, Barres BA, Bohlen CJ, Scherrer G (2017) Loss of mu opioid receptor signaling in nociceptors, but not microglia, abrogates morphine tolerance without disrupting analgesia. Nat Med 23:164-173.

Dina OA, Parada CA, Yeh J, Chen X, McCarter GC, Levine JD (2004) Integrin signaling in inflammatory and neuropathic pain in the rat. Eur J Neurosci 19:634-642.

Due MR, Piekarz AD, Wilson N, Feldman P, Ripsch MS, Chavez S, Yin H, Khanna R, White FA (2012) Neuroexcitatory effects of morphine-3glucuronide are dependent on toll-like receptor 4 signaling. J Neuroinflammation 9:200.

Ellis A, Grace PM, Wieseler J, Favret J, Springer K, Skarda B, Ayala M, Hutchinson MR, Falci S, Rice KC, Maier SF, Watkins LR (2016) Morphine amplifies mechanical allodynia via TLR4 in a rat model of spinal cord injury. Brain Behav Immun 58:348-356.

Fang X, Djouhri L, McMullan S, Berry C, Waxman SG, Okuse K, Lawson SN (2006) Intense isolectin-B4 binding in rat dorsal root ganglion neurons distinguishes $\mathrm{C}$-fiber nociceptors with broad action potentials and high Nav1.9 expression. J Neurosci 26:7281-7292.

Ferrari LF, Levine JD (2015) Plasma membrane mechanisms in a preclinical rat model of chronic pain. J Pain 16:60-66.

Ferrari LF, Bogen O, Chu C, Levine JD (2013) Peripheral administration of translation inhibitors reverses increased hyperalgesia in a model of chronic pain in the rat. J Pain 14:731-738.

Ferrari LF, Bogen O, Levine JD (2014) Second messengers mediating the expression of neuroplasticity in a model of chronic pain in the rat. J Pain 15:312-320.

Ferrari LF, Khomula EV, Araldi D, Levine JD (2016) Marked sexual dimorphism in the role of the ryanodine receptor in a model of pain chronification in the rat. Sci Rep 6:31221.

Ferrari LF, Araldi D, Bogen O, Green PG, Levine JD (2019) Systemic morphine produces dose-dependent nociceptor-mediated biphasic changes in nociceptive threshold and neuroplasticity. Neuroscience 398:64-75.

Ferrini F, Trang T, Mattioli TA, Laffray S, Del'Guidice T, Lorenzo LE, Castonguay A, Doyon N, Zhang W, Godin AG, Mohr D, Beggs S, Vandal K, Beaulieu JM, Cahill CM, Salter MW, De Koninck Y (2013) Morphine hyperalgesia gated through microglia-mediated disruption of neuronal $\mathrm{Cl}(-)$ homeostasis. Nat Neurosci 16:183-192.

Fukagawa H, Koyama T, Kakuyama M, Fukuda K (2013) Microglial activation involved in morphine tolerance is not mediated by toll-like receptor 4. J Anesth 27:93-97.

Grudt TJ, Williams JT (1994) mu-opioid agonists inhibit spinal trigeminal substantia gelatinosa neurons in guinea pig and rat. J Neurosci 14:16461654.

Horvath RJ, Romero-Sandoval EA, De Leo JA (2010) Inhibition of microglial P2X4 receptors attenuates morphine tolerance, Ibal, GFAP and mu opioid receptor protein expression while enhancing perivascular microglial ED2. Pain 150:401-413.

Hutchinson MR, Lewis SS, Coats BD, Rezvani N, Zhang Y, Wieseler JL, Somogyi AA, Yin H, Maier SF, Rice KC, Watkins LR (2010a) Possible involvement of toll-like receptor 4/myeloid differentiation factor- 2 activity of opioid inactive isomers causes spinal proinflammation and related behavioral consequences. Neuroscience 167:880-893.

Hutchinson MR, Zhang Y, Shridhar M, Evans JH, Buchanan MM, Zhao TX, Slivka PF, Coats BD, Rezvani N, Wieseler J, Hughes TS, Landgraf KE, Chan S, Fong S, Phipps S, Falke JJ, Leinwand LA, Maier SF, Yin H, Rice $\mathrm{KC}$, et al. (2010b) Evidence that opioids may have toll-like receptor 4 and MD-2 effects. Brain Behav Immun 24:83-95.

Hutchinson MR, Shavit Y, Grace PM, Rice KC, Maier SF, Watkins LR (2011) Exploring the neuroimmunopharmacology of opioids: an integrative re- view of mechanisms of central immune signaling and their implications for opioid analgesia. Pharmacol Rev 63:772-810.

Jacobsen JH, Watkins LR, Hutchinson MR (2014) Discovery of a novel site of opioid action at the innate immune pattern-recognition receptor TLR4 and its role in addiction. Int Rev Neurobiol 118:129-163.

Jensen TS (1997) Opioids in the brain: supraspinal mechanisms in pain control. Acta Anaesthesiol Scand 41:123-132.

Johnson JL, Rolan PE, Johnson ME, Bobrovskaya L, Williams DB, Johnson K, Tuke J, Hutchinson MR (2014) Codeine-induced hyperalgesia and allodynia: investigating the role of glial activation. Transl Psychiatry 4:e482.

Joseph EK, Levine JD (2010a) Hyperalgesic priming is restricted to isolectin B4-positive nociceptors. Neuroscience 169:431-435.

Joseph EK, Levine JD (2010b) Multiple PKCepsilon-dependent mechanisms mediating mechanical hyperalgesia. Pain 150:17-21.

Joseph EK, Chen X, Bogen O, Levine JD (2008) Oxaliplatin acts on IB4positive nociceptors to induce an oxidative stress-dependent acute painful peripheral neuropathy. J Pain 9:463-472.

Khasabov SG, Rogers SD, Ghilardi JR, Peters CM, Mantyh PW, Simone DA (2002) Spinal neurons that possess the substance $P$ receptor are required for the development of central sensitization. J Neurosci 22:9086-9098.

Khomula EV, Ferrari LF, Araldi D, Levine JD (2017) Sexual dimorphism in a reciprocal interaction of ryanodine and IP3 receptors in the induction of hyperalgesic priming. J Neurosci 37:2032-2044.

Kras JV, Weisshaar CL, Pall PS, Winkelstein BA (2015) Pain from intraarticular NGF or joint injury in the rat requires contributions from peptidergic joint afferents. Neurosci Lett 604:193-198.

Lai J, Gold MS, Kim CS, Bian D, Ossipov MH, Hunter JC, Porreca F (2002) Inhibition of neuropathic pain by decreased expression of the tetrodotoxin-resistant sodium channel, NaV1.8. Pain 95:143-152.

Lai J, Porreca F, Hunter JC, Gold MS (2004) Voltage-gated sodium channels and hyperalgesia. Annu Rev Pharmacol Toxicol 44:371-397.

Lewis SS, Hutchinson MR, Rezvani N, Loram LC, Zhang Y, Maier SF, Rice KC, Watkins LR (2010) Evidence that intrathecal morphine-3-glucuronide may cause pain enhancement via toll-like receptor 4/MD-2 and interleukin-1beta. Neuroscience 165:569-583.

Lipp J (1991) Possible mechanisms of morphine analgesia. Clin Neuropharmacol 14:131-147.

Mansour A, Lewis ME, Khachaturian H, Akil H, Watson SJ (1986) Pharmacological and anatomical evidence of selective mu, delta, and kappa opioid receptor binding in rat brain. Brain Res 399:69-79.

Matthes HW, Maldonado R, Simonin F, Valverde O, Slowe S, Kitchen I, Befort K, Dierich A, Le Meur M, Dollé P, Tzavara E, Hanoune J, Roques BP, Kieffer BL (1996) Loss of morphine-induced analgesia, reward effect and withdrawal symptoms in mice lacking the mu-opioid-receptor gene. Nature 383:819-823.

Mattioli TA, Leduc-Pessah H, Skelhorne-Gross G, Nicol CJ, Milne B, Trang T, Cahill CM (2014) Toll-like receptor 4 mutant and null mice retain morphine-induced tolerance, hyperalgesia, and physical dependence. PLoS One 9:e97361.

Mogensen TH (2009) Pathogen recognition and inflammatory signaling in innate immune defenses. Clin Microbiol Rev 22:240-273.

Nishiguchi J, Sasaki K, Seki S, Chancellor MB, Erickson KA, de Groat WC, Kumon H, Yoshimura N (2004) Effects of isolectin B4-conjugated saporin, a targeting cytotoxin, on bladder overactivity induced by bladder irritation. Eur J Neurosci 20:474-482.

Oliveira-Fusaro MCG, Zanoni CIS, Dos Santos GG, Manzo LP, Araldi D, Bonet IJM, Tambeli CH, Dias EV, Parada CA (2017) Antihyperalgesic effect of $\mathrm{CB} 1$ receptor activation involves the modulation of $\mathrm{P} 2 \mathrm{X} 3$ receptor in the primary afferent neuron. Eur J Pharmacol 798:113-121.

Parada CA, Yeh JJ, Joseph EK, Levine JD (2003a) Tumor necrosis factor receptor type-1 in sensory neurons contributes to induction of chronic enhancement of inflammatory hyperalgesia in rat. Eur J Neurosci 17: 1847-1852.

Parada CA, Yeh JJ, Reichling DB, Levine JD (2003b) Transient attenuation of protein kinase cepsilon can terminate a chronic hyperalgesic state in the rat. Neuroscience 120:219-226.

Pathan H, Williams J (2012) Basic opioid pharmacology: an update. Br J Pain 6:11-16.

Quanhong Z, Ying X, Moxi C, Tao X, Jing W, Xin Z, Li W, Derong C, Xiaoli Z, Wei J (2012) Intrathecal PLC(beta3) oligodeoxynucleotides antisense potentiates acute morphine efficacy and attenuates chronic morphine tolerance. Brain Res 1472:38-44. 
Reichling DB, Levine JD (2009) Critical role of nociceptor plasticity in chronic pain. Trends Neurosci 32:611-618.

Roeckel LA, Le Coz GM, Gavériaux-Ruff C, Simonin F (2016) Opioidinduced hyperalgesia: cellular and molecular mechanisms. Neuroscience 338:160-182.

Skolnick P, Davis H, Arnelle D, Deaver D (2014) Translational potential of naloxone and naltrexone as TLR4 antagonists. Trends Pharmacol Sci 35:431-432.

Song MJ, Wang YQ, Wu GC (2009) Additive anti-hyperalgesia of electroacupuncture and intrathecal antisense oligodeoxynucleotide to interleukin-1 receptor type I on carrageenan-induced inflammatory pain in rats. Brain Res Bull 78:335-341.

Sora I, Takahashi N, Funada M, Ujike H, Revay RS, Donovan DM, Miner LL, Uhl GR (1997) Opiate receptor knockout mice define mu receptor roles in endogenous nociceptive responses and morphine-induced analgesia. Proc Natl Acad Sci U S A 94:1544-1549.

Stein C, Schäfer M, Machelska H (2003) Attacking pain at its source: new perspectives on opioids. Nat Med 9:1003-1008.

Stiene-Martin A, Zhou R, Hauser KF (1998) Regional, developmental, and cell cycle-dependent differences in mu, delta, and kappa-opioid receptor expression among cultured mouse astrocytes. Glia 22:249-259.

Su L, Wang C, Yu YH, Ren YY, Xie KL, Wang GL (2011) Role of TRPM8 in dorsal root ganglion in nerve injury-induced chronic pain. BMC Neurosci 12:120.

Summer GJ, Romero-Sandoval EA, Bogen O, Dina OA, Khasar SG, Levine JD (2008) Proinflammatory cytokines mediating burn-injury pain. Pain 135:98-107.

Sun JL, Xiao C, Lu B, Zhang J, Yuan XZ, Chen W, Yu LN, Zhang FJ, Chen G, Yan M (2013) CX3CL1/CX3CR1 regulates nerve injury-induced pain hypersensitivity through the ERK5 signaling pathway. J Neurosci Res 91:545-553.

Taiwo YO, Levine JD (1989) Prostaglandin effects after elimination of indi- rect hyperalgesic mechanisms in the skin of the rat. Brain Res 492: 397-399.

Taiwo YO, Bjerknes LK, Goetzl EJ, Levine JD (1989) Mediation of primary afferent peripheral hyperalgesia by the cAMP second messenger system. Neuroscience 32:577-580.

Trafton JA, Abbadie C, Marek K, Basbaum AI (2000) Postsynaptic signaling via the $[\mathrm{mu}]$-opioid receptor: responses of dorsal horn neurons to exogenous opioids and noxious stimulation. J Neurosci 20:8578-8584.

Turchan-Cholewo J, Dimayuga FO, Ding Q, Keller JN, Hauser KF, Knapp PE, Bruce-Keller AJ (2008) Cell-specific actions of HIV-tat and morphine on opioid receptor expression in glia. J Neurosci Res 86:2100-2110.

Vierck CJ Jr, Kline RH, Wiley RG (2003) Intrathecal substance p-saporin attenuates operant escape from nociceptive thermal stimuli. Neuroscience 119:223-232.

Vulchanova L, Olson TH, Stone LS, Riedl MS, Elde R, Honda CN (2001) Cytotoxic targeting of isolectin IB4-binding sensory neurons. Neuroscience 108:143-155.

Wang X, Loram LC, Ramos K, de Jesus AJ, Thomas J, Cheng K, Reddy A, Somogyi AA, Hutchinson MR, Watkins LR, Yin H (2012) Morphine activates neuroinflammation in a manner parallel to endotoxin. Proc Natl Acad Sci U S A 109:6325-6330.

Watkins LR, Hutchinson MR, Rice KC, Maier SF (2009) The "toll" of opioid-induced glial activation: improving the clinical efficacy of opioids by targeting glia. Trends Pharmacol Sci 30:581-591.

Weisshaar CL, Winkelstein BA (2014) Ablating spinal NK1-bearing neurons eliminates the development of pain and reduces spinal neuronal hyperexcitability and inflammation from mechanical joint injury in the rat. J Pain 15:378-386.

Wiley RG, Kline RHt, Vierck CJ Jr (2007) Anti-nociceptive effects of selectively destroying substance $\mathrm{P}$ receptor-expressing dorsal horn neurons using [Sar9, Met $(\mathrm{O} 2) 11]$-substance P-saporin: behavioral and anatomical analyses Neuroscience 146:1333-1345. 